\title{
PENGARUH UNCONDITIONAL DAN CONDITIONAL CONSERVATISM TERHADAP FINANCIAL DISTRESS
}

\author{
Nanda Ismi Kumalawati \\ Institut Bisnis dan Informatika Kwik Kian Gie \\ nandaismikuamawati@gmail.com \\ Rizka Indri Arfianti \\ Institut Bisnis dan Informatika Kwik Kian Gie \\ rizka.indri@kwikkiangie.ac.id
}

\begin{abstract}
Financial distress is increasingly faced by some companies early in bankruptcy; it's usually caused by the improper basis of decision making and the unavailability of cash. Therefore, financial distress is very important to know as early as possible so it can be resolved and no bankruptcy happens. Conservatism is considered to be one factor that can reduce the risk of financial distress. So this study aims to examine the influence of conservatism on financial distress. The sample of the company used manufacturing companies during the period 2014-2016, this study also testing some companies that have experienced of financial distress during the period of observation. Data analysis techniques use multiple linear regression analysis. Through the results of this study, it can be concluded that unconditional conservatism and conditional conservatism proved to negatively affect financial distress.
\end{abstract}

Keywords: Financial Distress, Accounting Conservatism, Unconditional Conservatism, Conditional Conservatism

\section{PENDAHULUAN}

Salah satu sinyal dari perusahaan akan terjadinya kebangkrutan didapat dari timbulnya kondisi kesulitan keuangan atau financial distress. Kondisi seperti inilah yang membuat pemilik perusahaan, investor, dan kreditur menjadi khawatir jika perusahaan mengalami kerugian berkelanjutan ataupun mengalami gagal bayar yang dapat mengarah pada kebangrutan. Oleh karena itu financial distress sangatlah penting untuk diketahui sedini mungkin agar dapat segera diatasi sehingga tidak terjadi kebangkrutan.

Terdapat berbagai model pengukuran untuk memprediksi bahwa suatu perusahaan mengalami kondisi financial distress atau tidak. Diantaranya adalah model pengukuran Altman, Olshon, Zmijewki, Springate, dan masih banyak lagi. Disamping itu banyak penelitian terdahulu yang menguji financial distress melalui berbagai proksi rasio keuangan yang juga dianggap mampu untuk memprediksi kondisi financial distress. 
Berdasarkan penjabaran tersebut dapat penulis simpulkan bahwa kondisi financial distress dapat langsung diprediksi melalui laporan keuangan suatu perusahaan.

Laporan keuangan suatu perusahaan sangatlah penting bagi pihak internal maupun pihak eksternal untuk mengetahui kondisi perusahaan tersebut yang nantinya akan menjadi bahan pertimbangan atas keputusan yang akan diambil. Dalam pembuatan laporan keuangan suatu perusahaan pasti dilandasi oleh sebuah konsep akuntansi sehingga pada akhirnya para pengguna laporan keuangan tersebut dapat memperoleh informasi yang berguna untuk mengambil keputusan. Salah satu konsep akuntansi yang terkenal adalah konservatisme.

Beberapa peneliti menjelaskan manfaat penerapan konsep konservatisme yaitu mengurangi asimetri informasi melalui pengurangan cost of debt dan cost of equity ( $\mathrm{Li}, \quad 2010)$, membatasi pembayaran dividen yang terlalu tinggi karena mengurangi konflik debtholder dan shareholder terkait kebijakan dividen (Ahmed et al., 2002), dan mengurangi biaya agensi
(Watts, 2003), dan meningkatkan kualitas laba (Fala, 2007). Manfaat penerapan konsep konservatisme tersebut disinyalir dapat meningkatkan arus kas sehingga konservatisme dapat berperan dalam mengurangi kondisi financial distress karena pada dasarnya kepailitan merupakan suatu kondisi awal dari ketidakcukupan kas (Wulandari, 2012).

Dalam penelitian (Biddle, Kim, Ma, \& Song, 2010) ditemukan hasil bahwa konservatisme berpengaruh negatif terhadap kondisi financial distress. Hal ini dikarenakan konservatisme mengurangi asimetri informasi dan meningkatkan arus kas perusahaan, sehingga kemungkinan terjadinya kondisi financial distress dapat berkurang. Hasil penelitian ini sejalan dengan hasil penelitian (Zamani, Piri, \& Heidari, 2014) yang menyatakan bahwa konservatisme berpengaruh negatif terhadap financial distress. Namun berbeda dengan hasil penelitian (Wulandari, 2012) yang menyatakan bahwa konservatisme tidak berpengaruh terhadap financial distress. Beberapa peneliti sebelumnya juga membedakan konservatisme menjadi 


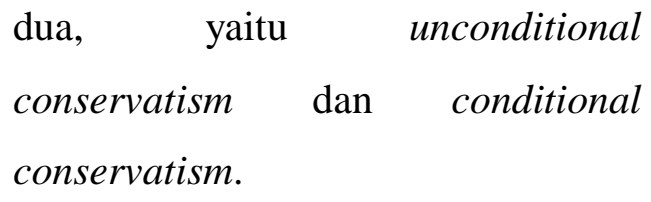

\section{Rumusan Masalah}

Berdasarkan latar belakang masalah yang telah dijelaskan sebelumnya, maka rumusan masalah dalam penelitian ini adalah "apakah unconditional conservatism dan conditional conservatism berpengaruh terhadap financial distress pada perusahaan manufaktur yang teraftar di BEI periode 2014 2016."

\section{Tujuan Penelitian}

Tujuan dari penelitian ini adalah menemukan bukti empiris tentang apakah unconditional conservatism dan conditional conservatism berpengaruh terhadap financial distress pada perusahaan manufaktur yang teraftar di BEI periode 2014 2016. Adapun manfaat dari kegiatan penelitian bagi peneliti adalah meningkatkan dan mengembangkan wawasan dan pengetahuan tentang akuntansi khususnya yang berhubungan dengan financial distress, sedangkan bagi pembaca lainnya, dapat dijadikan sebagai bahan tambahan informasi serta sebagai masukan untuk penelitian sejenis berikutnya yang berhubungan dengan financial distress.

\section{TELAAH LITERATUR}

\section{Teori Agensi}

Menurut Anthony dan Govidaradjan (2015: 269-273) teori agensi atau agency theory adalah hubungan atau kontrak antara prinsipal dan agen. Teori agensi memiliki asumsi bahwa tiap-tiap individu semata-mata termotivasi oleh kepentingan dirinya sendiri sehingga menimbulkan konflik kepentingan antara prinsipal dan agen.

Pada penelitian ini, teori agensi dapat menjelaskan bahwa agen dapat memanfaatkan konservatisme sebagai salah satu alternatif tindakan yang dapat dilakukan untuk menyelaraskan hubungan antar prinsipal dan agen sehingga meminimalisir adanya konflik kepentingan yang akan berdampak buruk bagi perusahaan dan membawa perusahaan dalam kondisi financial distress.

\section{Financial Distress}

Menurut Platt dan Platt (2002), financial distress adalah tahap penurunan kondisi keuangan yang terjadi sebelum terjadinya kepailitan 
ataupun likuidasi. Kegunaan informasi financial distress yang terjadi pada suatu perusahaan adalah:

1. Dapat mempercepat tindakan manajemen untuk mencegah masalah sebelum terjadinya kebangkrutan.

2. Pihak manajemen dapat mengambil tindakan merger atau takeover agar perusahaan lebih mampu untuk membayar utang dan mengelola perusahaan dengan lebih baik.

3. Memberikan tanda peringatan dini/awal adanya kebangkrutan pada masa yang akan datang.

Menurut Baldwin dan Mason (1983), suatu perusahaan mengalami financial distress apabila perusahaan tersebut tidak dapat memenuhi kewajiban finansialnya dengan dilanggarnya persyaratan utang (debt covenants) disertai penghapusan atau pengurangan pembiayaan dividen.

Wruck (1990) dalam Wardhani (2006), menyatakan bahwa perusahaan mengalami financial distress sebagai akibat dari permasalahan ekonomi, penurunan kinerja, dan manajemen yang buruk.

\section{Konservatisme}

Secara tradisional, konservatisme akuntansi dapat diartikan sebagai tidak mengantisipasi laba tetapi mengantisipasi semua kerugian (Bliss, 1924) dalam (Watts, 2003). Watts (2003) mendefinisikan konservatisme sebagai prinsip kehati-hatian dalam pelaporan keuangan dimana perusahaan tidak terburu-buru dalam mengakui dan mengukur aktiva dan laba serta segera mengakui kerugian dan hutang yang mempunyai kemungkinan yang terjadi. Givoly \& Hayn (2000) mendefinisikan konservatisme sebagai pengakuan awal untuk biaya dan rugi serta menunda pengakuan untuk pendapatan dan keuntungan.

Dalam Statement of Financial Accountig Concepts (SFAC) No. 2 disebutkan bahwa menurut Financial Accounting Standard Board (FASB), konservatisme didefinisikan sebagai sebuah reaksi kehati-hatian dalam menghadapi ketidakpastian yang melekat dalam perusahaan untuk mencoba memastikan bahwa ketidakpastian dan risiko inheren dalam lingkungan bisnis cukup dipertimbangkan. 
Beberapa peneliti membagi konservatisme menjadi dua jenis yaitu unconditional conservatism dan conditional conservatism. Unconditional conservatism adalah konservatisme yang berdasarkan akuntansi, terkait dengan neraca, dan tidak bergantung pada adanya berita baik atau buruk, atau dengan kata lain bersifat independen dari adanya berita baik atau buruk di lingkungan bisnis. Sedangkan conditional concervatism dimana konservatisme kodisional ini berdasarkan pada kondisi pasar, terkait dengan laba atau rugi dan bergantung pada berita (news dependent), maksudnya bahwa konservatisme bentuk ini merupakan reaksi atau tanggapan dari perusahaan yang melakukan verifikasi yang berbeda sebagai penyerapan informasi yang terdapat dalam lingkungan bisnis yang dapat memengaruhi earnings perusahaan.

FASB berargumen bahwa konservatisme dapat menghasilkan asimetri informasi yang dapat mengurangi pengetahuan investor mengenai arus kas masa depan (Biddle et al., 2010). Sehingga FASB dan IASB kemudian menghapus konsep konservatisme tersebut dari kerangka konseptual mereka pada tahun 2010. Penghapusan ini dilakukan karena konsep konservatisme dianggap telah melanggar netralitras karena pada dasarnya laporan keuangan disiapkan agar dapat memberikan informasi yang berguna dan dapat terhindar dari bias.

Namun tidak semua berpandangan bahwa konservatisme itu buruk, ada juga yang tetap mendukung konsep konservatisme. Beberapa peneliti menjelaskan manfaat penerapan konsep konservatisme yaitu mengurangi asimetri informasi melalui pengurangan cost of debt dan cost of equity (Li, 2010), membatasi pembayaran dividen yang terlalu tinggi karena mengurangi konflik debtholder dan shareholder terkait kebijakan dividen (Ahmed et al., 2002), dan mengurangi biaya agensi (Watts, 2003), dan meningkatkan kualitas laba (Fala, 2007).

Penerapan IFRS di Indonesia menyebabkan pergeseran pada konsep konservatisme. IFRS lebih berfokus pada penyajian laporan keuangan yang relevan sehingga menyebabkan ketergantungan yang semakin tinggi terhadap estimasi dan 
berbagai judgement. Selain itu IFRS berdasarkan prinsipal based lebih banyak menggunakan professional judgement dalam melakukan penilaian suatu akun. Professional judgement ini membuat perusahaan menjadi lebih optimis karena dapat mengakui perubahan nilai suatu akun sesuai dengan nilai wajar.

Konsep konservatisme semakin mengalami pergeseran ketika IASB memperkenalkan sebuah prinsip baru yaitu prudence. Dimana prudence merupakan prinsip kehati-hatian yang memperbolehkan manajer mengakui pendapatan meskipun masih berupa potensi sepanjang memenuhi ketentuan pengakuan pendapatan (revenue recognition) dalam IFRS. Akan tetapi konservatisme masih perlu untuk dipertimbangkan karena pada dasarnya kedua prinsip tersebut tidak jauh berbeda karena kedua prinsip mengandung unsur kehati-hatian manajemen dalam pembuatan laporan keuangan (Merselina, 2016).

\section{Pengaruh \\ Unconditional conservatism terhadap financial distress}

Givoly dan Hayn (2000) berpendapat bahwa konservatisme jenis ini terjadi ketika jumlah arus kas operasi lebih besar dari pada jumlah laba bersih. Adanya peningkatan arus kas juga dapat mengurangi risiko terjadinya financial distress karena pada dasarnya kepailitan merupakan suatu kondisi awal dari ketidakcukupan kas (Wulandari, 2012). Kemampuan unconditional conservatism untuk mengurangi risiko terjadinya financial distress juga didukung oleh penelitian Poorzamani dan Anhari (2013).
$\mathrm{H}_{1}$ : Unconditional conservatism berpengaruh negatif terhadap financial distress.

\section{Pengaruh Conditional conservatism terhadap financial distress}

Zhang (2008) berpendapat konservatisme jenis ini terjadi jika non operating accrual lebih besar dari total accrual. Hal tersebut menggambarkan perusahaan cenderung lebih sering mengakui losses ataupun beban bahkan yang bukan merupakan losses ataupun beban operational lebih cepat bahkan sebelum benar-benar terjadi. Konservatisme jenis ini membantu 
perusahaan mengantisipasi segala bentuk kerugian yang akan terjadi sehingga perusahaan dapat mengambil keputusan yang tepat agar terhindar dari segala bentuk kerugian yang dapat mengancam keberlangsungan operasi perusahaan. Hal itulah yang dapat menggambarkan bahwa conditional conservatism dapat mengurangi risiko terjadinya financial distress pada perusahaan. Hal tersebut didukung juga oleh penelitian Mamaghani dan Darabi (2016) dan Moridipour et al. (2014).

$\mathrm{H} 2$ : Conditional conservatism berpengaruh negatif terhadap financial distress.

\section{METODOLOGI PENELITIAN}

\section{Objek Penelitian}

Objek penelitian yang akan digunakan adalah perusahaan manufaktur yang terdaftar di Bursa Efek Indonesia (BEI) selama periode tahun 2014-2016 untuk tahun buku laporan keuangan yang berakhir pada 31 Desember. Alasan yang melatarbelakangi pemilihan perusahaan manufaktur menjadi objek penelitian ini adalah karena perusahaan manufaktur merupakan perusahaan yang dominan di
Indonesia. Penelitian ini juga melakukan pengujian lebih lanjut terhadap sampel perusahaan yang pernah mengalami kondisi financial distress yang ditandai dengan nilai $Z$ score nya yang termasuk dalam kategori distress area.

\section{Variabel Penelitian}

1. Variabel Dependen

Variabel dependen dalam penelitian ini adalah Financial Distress. Pengukuran financial distress pada penelitian ini menggunakan model pengukuran Altman Z Score yang dikembangkan oleh Edward I. Altman (1968). Model pengukuran ini mengakategorikan Z Score pada 3 kondisi yaitu, Safe Area, Grey Area, Distress Area. Namun pada penelitian kali ini, penulis tidak mengkategorikan Z Score tersebut melainkan mengalikan nilai $Z$ score tersebut dengan negatif satu (-1). Hal ini akan membuat perusahaan yang memiliki Z Score lebih tinggi maka perusahaan tersebutlah yang cenderung mengalami kondisi financial distress, hal ini sama seperti yang dilakukan Deviacita dan Achmad (2012). Model pengukuran 
financial distress adalah sebagai berikut:

$$
\text { Un Con }=\frac{\text { NI }- \text { CFO }}{\text { Total Assets }} *(-1)
$$

$$
\begin{aligned}
& \text { FD }=(1,2 \times 1+1,4 \times 2+3,3 \times 3+ \\
& 0,64 X 4+1,0 \times 5) *(-1)
\end{aligned}
$$

Keterangan:

$\mathrm{FD}=$ Tingkat financial distress

$\mathrm{X} 1=($ Current Assets - Current Liabilities)/ Total Assets

$\mathrm{X} 2=$ Retained Earnings $/$ Total Assets

$\mathrm{X} 3$ = Earnings before Interest and Taxes / Total Assets

X4 = Market Value of Equity / Total Liabilities

X5 = Sales / Total Assets

2. Variabel Independen

\section{Unconditional Conservatism}

Pengukuran konservatisme yang dikembangkan oleh Givoly dan Hayn (2000), menggunakan total akrual yaitu perbedaan antara laba bersih dengan arus kas operasi. Pada penelitian ini total akrual tersebut menjadi pengurukuran variabel unconditional conservatism. Model pengukuran variabel unconditional conservatism pada penelitian ini sama seperti yang digunakan oleh Apriani et al. (2015) sebagai berikut:
Keterangan:

UnCon $=$ Tingkat unconditional
conservatism $\mathrm{NI}=$ Laba bersih sebelum extraordinary.item dikurangi depresiasi dan amortisasi

$\mathrm{CFO}=$ Arus kas dari kegiatan operasional

\section{Conditional Conservatism}

Zhang (2008) mengembangkan pengukuran konservatisme menggunakan non-operating accrual. Pada penelitian ini nonoperating accrual tersebut menjadi pengukuran variabel conditional conservatism. Model pengukuran variabel conditional conservatism pada penelitian ini sama seperti yang dilakukan Haniati dan Fitriany (2010) sebagai berikut:

$$
\text { Cc Con }=\frac{\text { TA }- \text { OA }}{\text { Total Assets }} *(-1)
$$

$$
\begin{aligned}
\mathbf{O A} & =\Delta \mathbf{A} / \mathbf{R}+\Delta \mathbf{I n v}+\Delta \mathbf{P E}-\Delta \mathbf{A} / \mathbf{P} \\
& -\Delta \mathbf{T P}
\end{aligned}
$$

Keterangan:

Cc Con $=$ Tingkat conditional conservatism

TA $=$ Total akrual 
OA $=$ Akrual operasi

$\Delta \mathrm{A} / \mathrm{R}=$ Perubahan jumlah piutang usaha

$\Delta \mathrm{Inv}=$ Perubahan jumlah persediaan

$\Delta \mathrm{PE}=$ Perubahan jumlah beban dibayar dimuka

$\Delta \mathrm{A} / \mathrm{P}=$ Perubahan jumlah hutang usaha

$\Delta \mathrm{TP}=$ Perubahan jumlah hutang pajak

\section{Variabel Kontrol}

Ukuran Perusahaan/Size

Ukuran perusahaan dapat memberikan skala ataupun gambaran mengenai besar kecilnya sebuah perusahaan. Biasanya ukuran perusahaan dapat diukur dari jumlah aset yang dimilikinya. Semakin besar jumlah aset yang dimiliki suatu perusahaan maka kondisi keuangan perusahaan tersebut akan lebih kuat dan lebih stabil sehingga jauh dari kondisi financial distress. Variabel ukuran perusahaan pada penelitian ini menggunakan proksi yang juga digunakan oleh Poorzamani dan Anhari (2013) yaitu natural logaritma total aset.

Size = Natural Logaritma $($ Ln) Total Aset
Leverage

Beberapa perusahaan yang mengalami kondisi financial distress diawali dengan ketidakmampuan perusahaan tersebut membayar hutang. Sehingga leverage menjadi unsur yang sangat penting dalam memprediksi financial distress karena dapat menggambarkan sampai sejauh mana kemampuan perusahaan dapat membayar hutanghutangnya kepada pihak luar apabila diukur dari modal yang dimiliki perusahaan. Variabel leverage pada penelitian ini menggunakan proksi yang juga digunakan oleh Wulandari (2012) yaitu debt to equity ratio sebagai berikut:

$$
\text { Lev }=\frac{\text { Total Hutang }}{\text { Total Ekuitas }}
$$

Pertumbuhan Penjualan/Sales Growth

Pertumbuhan penjualan mencerminkan kemampuan perusahaan dalam meningkatkan jumlah penjualan produk mereka dari tahun ke tahun. Besarnya pertumbuhan penjualan akan berpengaruh besar terhadap kondisi perusahaan di kemudian hari karena menandakan perusahaan masih dapat terus menjual produk mereka yang 
menjadi sumber terbesar perusahaan tersebut dalam memperoleh laba, sehingga perusahaan dengan tingkat pertumbuhan penjualan yang tinggi cenderung terhindar dari kondisi financial distress.Pertumbuhan penjualan diukur menggunakan proksi yang juga digunakan oleh Widhiari dan Merkusiwati (2015) sebagai berikut:

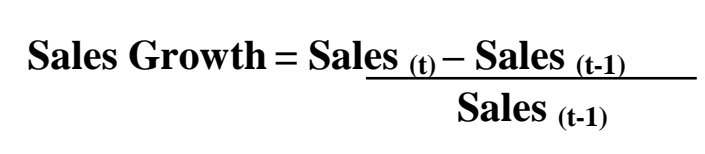

Keterangan:

Sales $_{(t)}$ : Total penjualan pada tahun pengamatan

Sales ${ }_{(t-1)}$ : Total penjualan 1 tahun sebelum tahun pengamatan

\section{Kinerja Perusahaan}

Kinerja perusahaan merupakan hasil serangkaian proses bisnis yang mengorbankan sumber daya yang dimiliki perusahaan. Kinerja perusahaan dapat diukur melalui informasi keuangan maupun non keuangan. Semakin baik kinerja perusahaan maka akan menunjukan semakin efisien dan efektif perusahaan mengelola sumber daya dalam menghasilkan laba yang semaksimal mungkin sehingga perusahaan dapat terhindar dari kondisi financial distress. Kinerja perusahaan diproksikan dengan nilai Tobins $Q$ yang dikembangkan oleh Tobin (1969) dan kemudian dimodifikasi oleh Chung dan Pruitt (1994) sebagai berikut:

$$
\text { Tobins } \mathbf{Q}=\frac{\text { MVE-Debt }}{\text { Total Assets }}
$$

Debt $=($ Current Liabilities - Current Assets $)+$ Long Term Liabilities

Keterangan:

MVE = Nilai pasar ekuitas / Market value of equity yang diperoleh dari jumlah saham beredar dikali dengan closing price pada tahun pengamatan Umur Perusahaan/Age

Perusahaan yang sudah lama beroperasi dapat mencerminkan lamanya perusahaan tersebut dapat bertahan dari kebangkrutan maupun kondisi financial distress yang selalu mengancam setiap perusahaan. Variabel umur diukur dengan selisih jumlah tahun dihitung dari saat perusahaan berdiri sampai dengan tahun pengamatan. Hal ini sama seperti yang dilakukan oleh Ramadhani dan Lukviarman (2009).

\section{Teknik Pengumpulan Data}

Teknik pengumpulan data untuk penelitian ini dilakukan dengan cara 
observasi data sekunder pada laporan tahunan perusahaan manufaktur yang terdaftar di Bursa Efek Indonesia selama 2014-2016.

\section{Teknik Pengambilan Sampel}

Teknik pengambilan sampel yang digunakan adalah non-probability sampling, yaitu purposive sampling, dimana sampel yang dijadikan objek penelitian ditentukan berdasarkan kriteria tertentu. Kriteria yang ditetapkan untuk mengambil sampel dalam penelitian ini adalah sebagai berikut:

1. Perusahaan yang terdaftar di BEI dan tergolong dalam perusahaan manufaktur sebelum 2014 hingga tahun 2016.

2. Tidak mengalami delisting selama tahun periode pengamatan.

3. Perusahaan menerbitkan laporan keuangan yang berakhir 31 Desember tiap tahun pengamatan dan disajikan dalam rupiah.
4. Mempunyai data-data yang lengkap sesuai dengan indikator atau proksi pengukuran variabelvariabel yang dibutuhkan.

Terdapat kriteria khusus yang ditetapkan untuk mengambil sampel yang termasuk dalam pengujian tambahan yaitu pernah mengalami kondisi financial distress selama periode pengamatan yang ditentukan dengan nilai $Z$ score perusahaan termasuk dalam kategori distress area yaitu kurang dari 1,8 (Altman, 1968).

\section{Teknik Analisis Data}

Metode statistik yang digunakan dalam penelitian ini adalah Regresi Linear Berganda.

Tahap-tahap dalam menganalisa data adalah sebagai berikut:

1. Uji kesamaan koefisien (pooling)

2. Uji asumsi klasik

3. Uji F

4. Uji t

5. Uji koefisien determinasi 


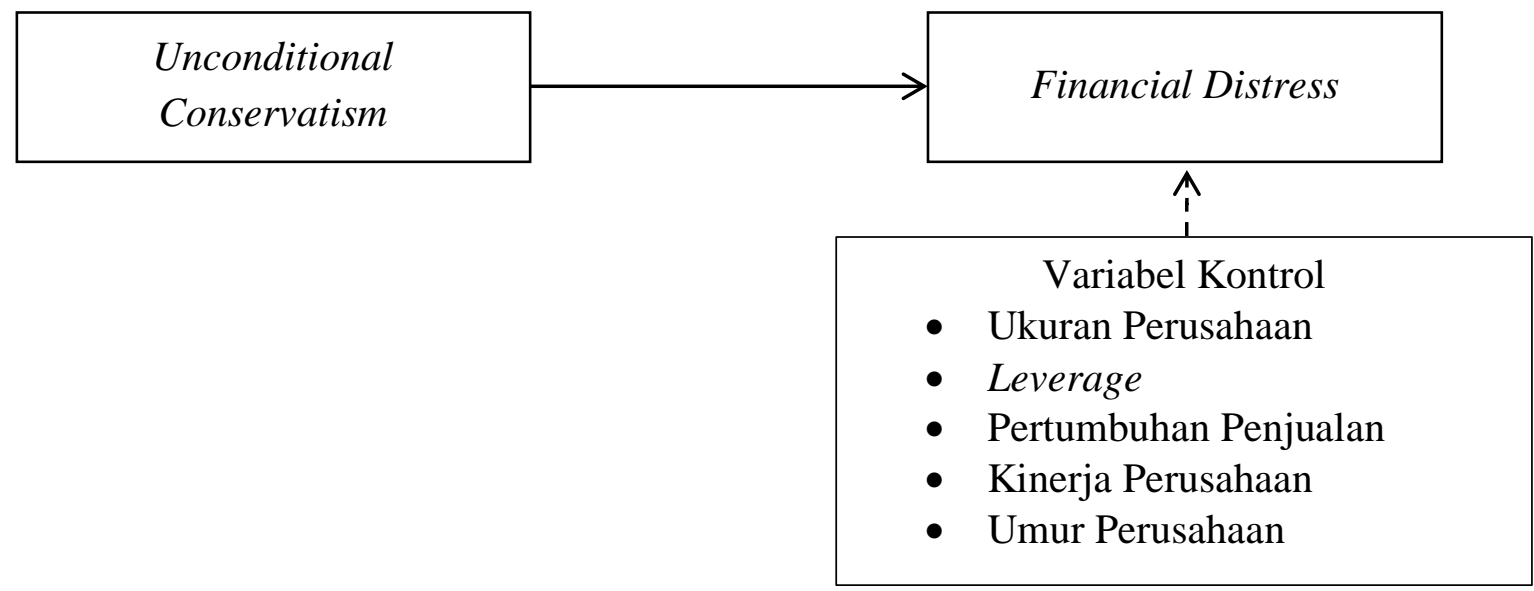

Gambar 1. Kerangka Konseptual Model Regresi (1)

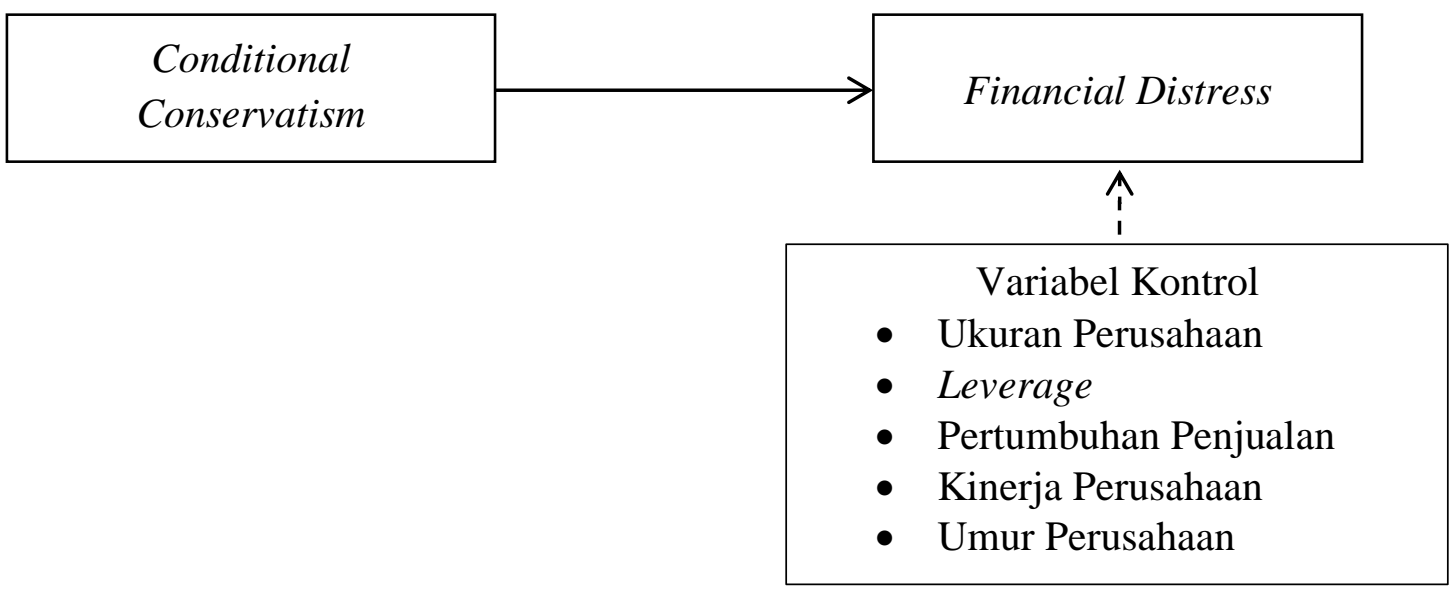

Gambar 2. Kerangka Konseptual Model Regresi (2)

4. HASIL \& ANALISIS

\section{Gambaran Umum Objek}

\section{Penelitian}

Objek penelitian yang akan digunakan adalah perusahaan manufaktur yang terdaftar di Bursa Efek Indonesia selama periode tahun 2014-2016 untuk tahun buku laporan keuangan yang berakhir pada 31 Desember. Jumlah keseluruhan sampel yang dijadikan objek penelitian adalah sebanyak 93 perusahaan, sedangkan jumlah sampel yang masuk dalam pengujian tambahan sebanyak 30 perusahaan. Namun setelah melewati uji asumsi klasik ditemukan data tidak berdistribusi normal sehingga penulis membuang beberapa data outlier sehingga jumlah keseluruhan sampel sebanyak 84 perusahaan dan jumlah 
sampel perusahaan distress sebanyak 27 perusahaan.

Tabel 1. Hasil Statistik Deskriptif Keseluruhan

\begin{tabular}{lrrrr}
\hline Variable & Minimum & Maximum & Mean & $\begin{array}{c}\text { Std. } \\
\text { Deviation }\end{array}$ \\
\hline FDscore & -32.367 & 2.186 & -4.297 & 4.687 \\
UnCon & -1.418 & 0.164 & -0.284 & 0.221 \\
CcCon & -1.421 & 0.241 & -0.269 & 0.224 \\
Size & 10.753 & 19.383 & 14.487 & 1.694 \\
Lev & -4.448 & 5.395 & 1.011 & 1.209 \\
SalesGrowth & -0.999 & 0.787 & 0.037 & 0.192 \\
TobinsQ & -0.350 & 6.904 & 1.203 & 1.223 \\
Age & 10.000 & 86.000 & 38.952 & 13.781 \\
\hline
\end{tabular}

Tabel 2. Hasil Statistik Deskriptif Sampel Perusahaan Distress

\begin{tabular}{lrrrr}
\hline Variable & Minimum & Maximum & Mean & $\begin{array}{c}\text { Std. } \\
\text { Deviation }\end{array}$ \\
\hline FDscore & -3.213 & -0.070 & -1.448 & 0.622 \\
UnCon & -0.891 & 0.164 & -0.288 & 0.210 \\
CcCon & -0.901 & 0.006 & -0.289 & 0.205 \\
Size & 12.287 & 17.059 & 14.830 & 1.236 \\
Lev & 0.198 & 5.395 & 2.000 & 1.299 \\
SalesGrowth & -0.999 & 0.709 & -0.011 & 0.220 \\
TobinsQ & -0.017 & 1.563 & 0.561 & 0.327 \\
Age & 10.000 & 69.000 & 37.630 & 13.129 \\
\hline
\end{tabular}

Tabel 3. Hasil Uji Kesamaan Koefisien

\begin{tabular}{lcclccc}
\hline \multicolumn{3}{c}{ Model 1 } & & & \multicolumn{2}{c}{ Model 2 } \\
Variable & \multicolumn{2}{c}{ Sig. } & & \multicolumn{2}{c}{ Sig. } \\
& 83 & $\begin{array}{c}27 \\
\text { Perusahaan }\end{array}$ & $\begin{array}{c}\text { Perusahaan } \\
\text { Distress }\end{array}$ & & & 27 \\
DT1_Uncon & 0.856 & 0.923 & DT1_Cccon & 0.921 & 0.995 \\
DT1_Size & 0.299 & 0.587 & DT1_Size & 0.291 & 0.667 \\
DT1_Lev & 0.185 & 0.702 & DT1_Lev & 0.173 & 0.625 \\
DT1_SG & 1.000 & 0.057 & DT1_SG & 0.979 & 0.071 \\
DT1_TB & 0.081 & 0.906 & DT1_TB & 0.082 & 0.769 \\
DT1_Age & 0.174 & 0.867 & DT1_Age & 0.180 & 0.962 \\
DT2_Uncon & 0.348 & 0.370 & DT2_Cccon & 0.284 & 0.183 \\
\hline
\end{tabular}




\begin{tabular}{lcclccc}
\hline \multicolumn{3}{c}{ Model 1 } & & & Model 2 \\
Variable & \multicolumn{2}{c}{ Sig. } & & \multicolumn{2}{c}{ Sig. } \\
& 83 & $\begin{array}{c}27 \\
\text { Perusahaan }\end{array}$ & $\begin{array}{c}\text { Perusahaan } \\
\text { Distress }\end{array}$ & Variable & 83 & 27 \\
Perusahaan & $\begin{array}{c}\text { Perusahaan } \\
\text { Distress }\end{array}$ \\
\hline DT2_Size & 0.943 & 0.128 & DT2_Size & 0.957 & 0.108 \\
DT2_Lev & 0.174 & 0.772 & DT2_Lev & 0.164 & 0.773 \\
DT2_SG & 0.353 & 0.224 & DT2_SG & 0.417 & 0.323 \\
DT2_TB & 0.083 & 0.094 & DT2_TB & 0.101 & 0.068 \\
DT2_Age & 0.151 & 0.933 & DT2_Age & 0.155 & 0.946 \\
\hline
\end{tabular}

\section{Hasil Analisis Statistik Deskriptif}

Hasil uji statistik deskriptif menunjukan bahwa nilai rata-rata variabel financial distress sebesar 4,297 yang berarti rata-rata perusahaan manufaktur di Indonesia tidak mengalami kondisi financial distress. Nilai minimum variabel financial distress sebesar $-32,367$ yang diperoleh dari PT Industri Jamu dan Farmasi Sido Muncul Tbk dan nilai maksimum variabel financial distress 2.186 yang diperoleh dari PT Jakarta Kyoei Steel Works Tbk. Nilai standar deviasi variabel financial distress sebesar 4,687. Nilai rata-rata variabel unconditional conservatism pada seluruh perusahaan sampel dan pada 27 perusahaan distress hampir sama yaitu sebesar -0,284 dan -
0,288. Nilai rata-rata variabel conditional conservatism pada seluruh perusahaan sampel dan pada 27 perusahaan distress masingmasing sebesar $-0,269$ dan $-0,289$ (seluruh hasil uji statistik deskriptif dapat dilihat pada Tabel 1 dan Tabel 2.

\section{Uji Kesamaan Koefisien}

Berdasarkan hasil uji kesamaan koefisien pada Tabel 3 di Lampiran C, baik pada keseluruhan sampel perusahaan maupun pada perusahaan yang pernah mengalami financial distress, menunjukan nilai sig $\geq \alpha=$ 5\% untuk seluruh koefisien variabel dummy sehingga data dapat di-pool atau diregresikan secara bersamaan dari tahun 2014-2016. 
Tabel 4. Hasil Uji Normalitas

One-Sample Kolmogorov-Smirnov Test

Keseluruhan Sampel Sampel Perusahaan Distress

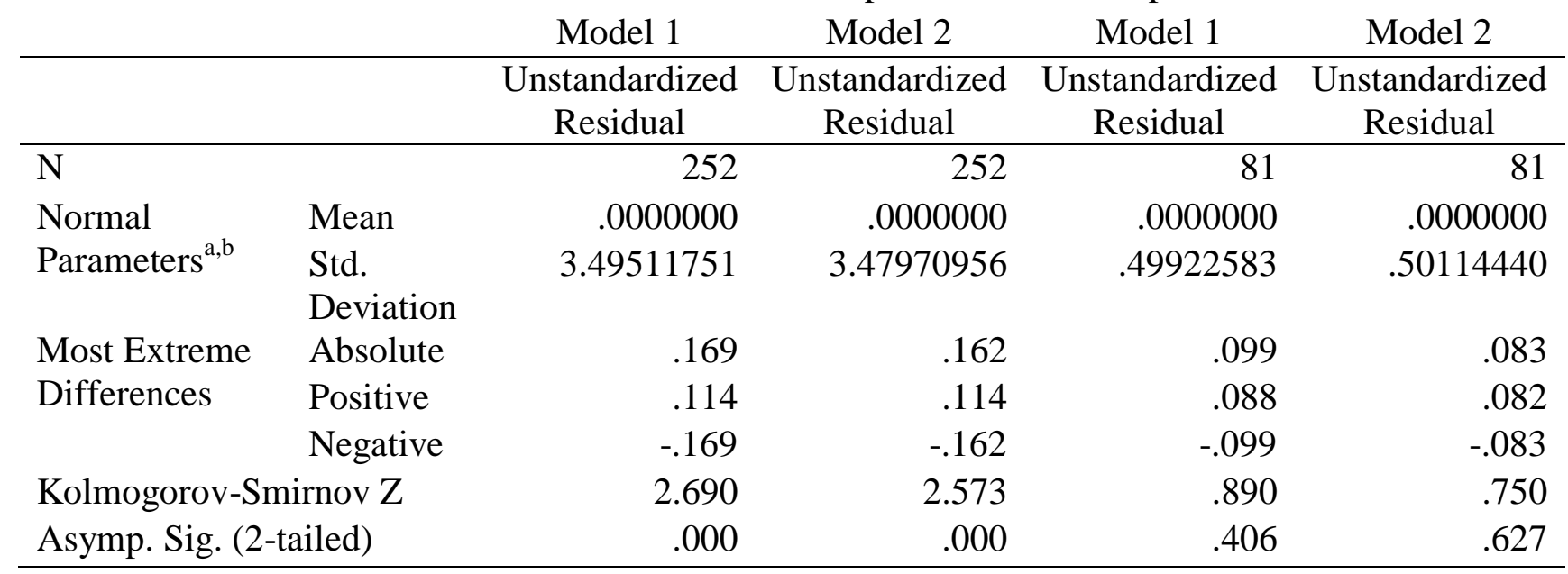
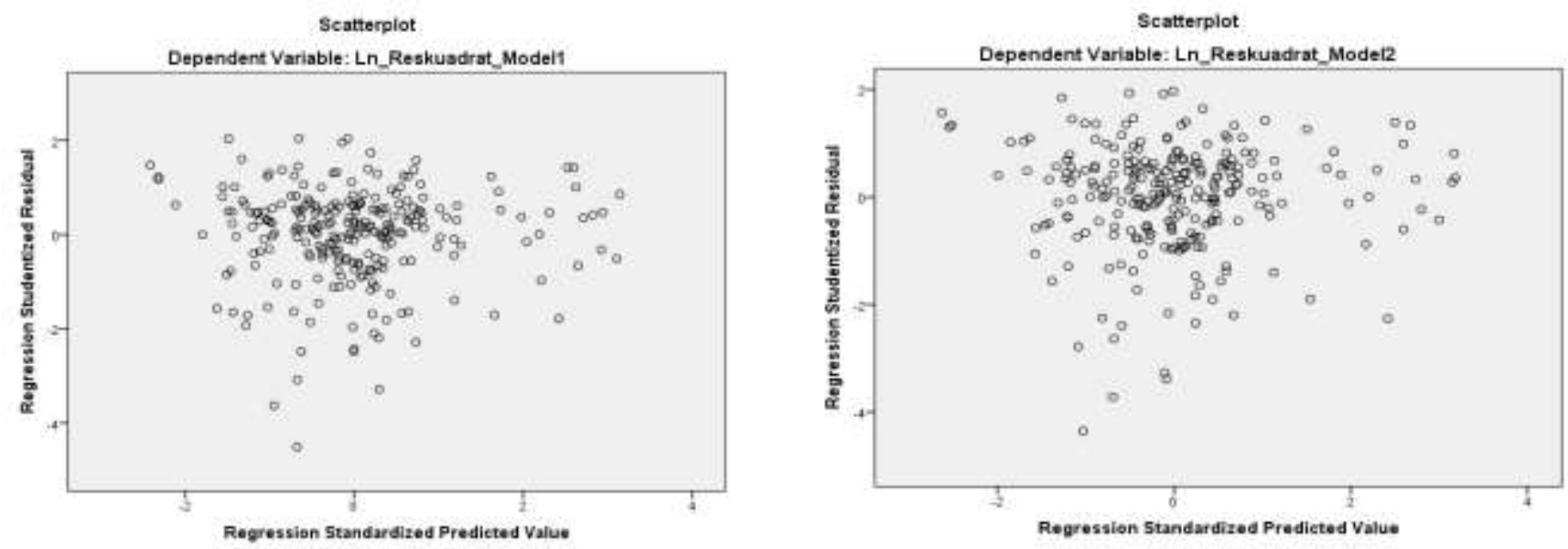

Gambar 3. Hasil Uji Heteroskedastisitas Keseluruhan Sampel

Tabel 5. Hasil Uji Heteroskedastisitas Sampel Perusahaan Distress

\begin{tabular}{lcclrl}
\hline Model 1 & $\mathrm{t}$ & Sig. & Model 2 & t & \multicolumn{1}{l}{ Sig. } \\
\hline (Constant) & 2.397 & 0.019 & (Constant) & 2.573 & 0.012 \\
Uncon & 0.850 & 0.398 & Cccon & 1.123 & 0.265 \\
Size & -1.045 & 0.300 & Size & -1.168 & 0.247 \\
Lev & -0.699 & 0.487 & Lev & -0.805 & 0.423 \\
SalesGrowth & 0.321 & 0.749 & SalesGrowth & 0.271 & 0.787 \\
TobinsQ & -0.560 & 0.577 & TobinsQ & -0.533 & 0.596 \\
Age & -1.224 & 0.225 & Age & -1.137 & 0.259 \\
\hline
\end{tabular}


Tabel 6. Hasil Uji Autokorelasi

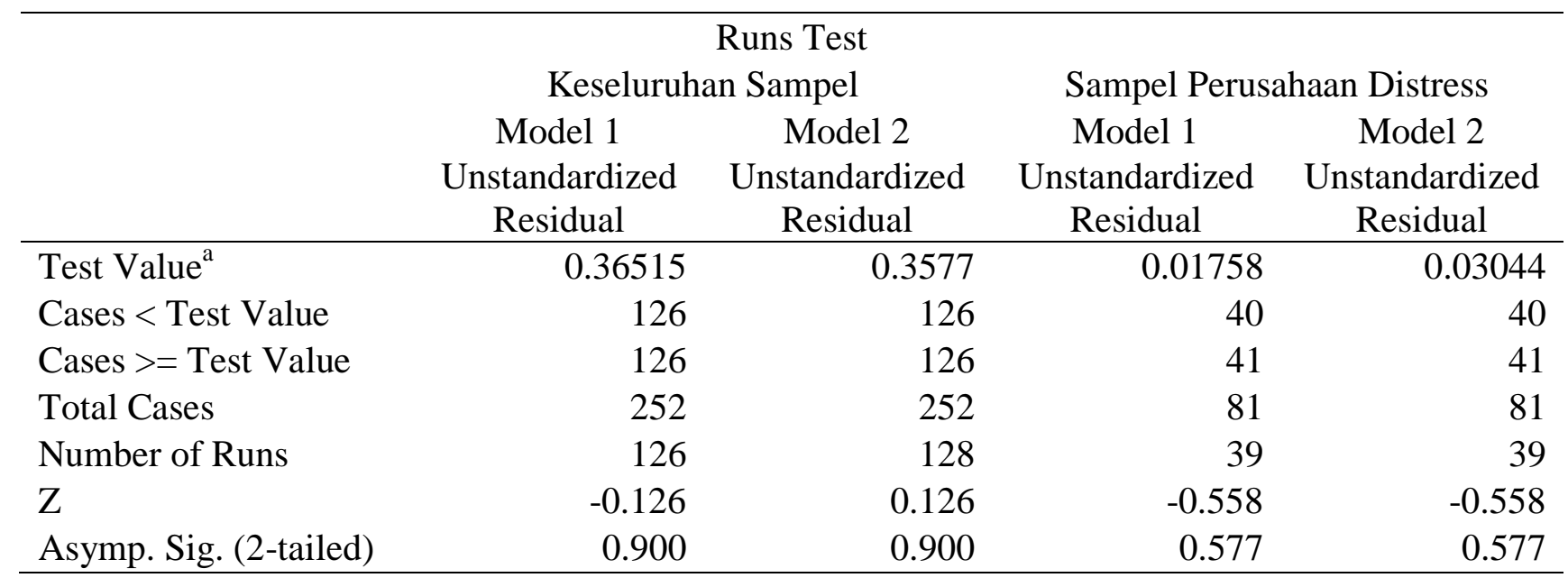

Tabel 7. Hasil Uji Multikolinieritas

\begin{tabular}{|c|c|c|c|c|}
\hline Model & \multicolumn{2}{|c|}{$\begin{array}{l}\text { Keseluruhan } \\
\text { Sampel }\end{array}$} & \multicolumn{2}{|c|}{$\begin{array}{c}\text { Sampel Perusahaan } \\
\text { Distress }\end{array}$} \\
\hline Model 1 & \multicolumn{2}{|c|}{$\begin{array}{l}\text { Collinearity } \\
\text { Statistics }\end{array}$} & \multicolumn{2}{|c|}{ Collinearity Statistics } \\
\hline \multicolumn{5}{|l|}{ (Constant) } \\
\hline UnCon & 0.916 & 1.091 & 0.92 & 1.086 \\
\hline Size & 0.785 & 1.275 & 0.808 & 1.238 \\
\hline Lev & 0.808 & 1.238 & 0.829 & 1.206 \\
\hline SalesGrowth & 0.962 & 1.040 & 0.975 & 1.025 \\
\hline TobinsQ & 0.929 & 1.077 & 0.957 & 1.045 \\
\hline Age & 0.844 & 1.185 & 0.839 & 1.191 \\
\hline Model 2 & \multicolumn{2}{|c|}{$\begin{array}{l}\text { Collinearity } \\
\text { Statistics }\end{array}$} & \multicolumn{2}{|c|}{ Collinearity Statistics } \\
\hline (Constant) & Tolerance & VIF & Tolerance & VIF \\
\hline CcCon & 0.882 & 1.133 & 0.879 & 1.138 \\
\hline Size & 0.786 & 1.272 & 0.803 & 1.246 \\
\hline Lev & 0.808 & 1.238 & 0.829 & 1.207 \\
\hline SalesGrowth & 0.923 & 1.084 & 0.955 & 1.047 \\
\hline TobinsQ & 0.927 & 1.079 & 0.954 & 1.048 \\
\hline Age & 0.843 & 1.186 & 0.824 & 1.214 \\
\hline
\end{tabular}




\section{Uji Asumsi Klasik}

Berdasarkan hasil uji normalitas dengan menggunakan One Sample Kolmogorov-Smirnov pada Tabel 4, pada keseluruhan sampel diperoleh nilai Asymp Sig. (2-tailed) < nilai $\alpha$ $(\alpha=5 \%)$ yaitu sebesar 0,000 yang berarti data tidak berdistribusi normal meskipun telah menggunakan metode outlier. Namun menurut Bowerman dan O'connel (2009), apabila jumlah sampel $\geq 30$ maka seluruh populasi dikatakan berdistribusi normal. Sedangkan pada sampel perusahaan distress diperoleh nilai 0,406 untuk variabel unconditional conservatism dan 0,627 untuk variabel conditional conservatism. Sehingga keduanya > nilai $\alpha(\alpha=5 \%)$ yang berarti data pada kedua model penelitian berdistribusi normal.

Uji heteroskedastisitas pada keseluruhan sampel menggunakan grafik scatterplot pada Gambar 3, yang menunjukan data cenderung tersebar diatas dan dibawah batas 0 , maka tidak terjadi heterokedastisitas. Sedangkan pada sampel perusahaan distress menggunakan uji glejser yang dapat dilihat pada Tabel 5, yang menunjukan semua variabel independen menunjukan nilai $\operatorname{sig} \geq \alpha$ $=5 \%$, maka tidak terjadi heterokedastisitas.

Berdasarkan tabel collinearity statistics yang dapat dilihat pada Tabel 7, pada pengujian keseluruhan sampel maupun pada sampel perusahaan distress, menunjukan semua variabel independen menghasilkan nilai tolerance $\geq 0.10$ dan nilai $\mathrm{VIF} \leq 10$, maka tidak terjadi multikolinieritas.

Berdasarkan hasil uji Runs yang dapat dilihat pada Tabel 6, pada keseluruhan sampel, menunjukan nilai Asymp Sig. 0,900 sedangkan pada sampel perusahaan distress menunjukan nilai Asymp Sig. 0,577 sehingga keduanya $>$ nilai $\alpha=5 \%$ maka tidak terdapat autokorelasi. 
Tabel 8. Hasil Uji F dan Uji t

Model 1

Keseluruhan Sampel

\begin{tabular}{lcccccccc}
\hline & \multicolumn{3}{c}{ Unstandardized } & \multicolumn{5}{c}{ Unstandardized } \\
\multicolumn{1}{c}{ Variabel } & Coefficients & Sig. t & Sig. F & \multicolumn{2}{c}{ Coefficients } & Sig. t & Sig. t \\
& B & Std. & & & B & Std. & & \\
& & Error & & & & Error & & \\
\hline (Constant) & 1.073 & 2.095 & 0.609 & 0.000 & -3.512 & 0.748 & 0.000 & 0.000 \\
UnCon & -1.333 & 1.058 & 0.209 & & -0.5 & 0.288 & 0.087 & \\
Size & 0.003 & 0.149 & 0.986 & & 0.144 & 0.052 & 0.007 & \\
Lev & 0.425 & 0.206 & 0.040 & & 0.14 & 0.049 & 0.005 & \\
SalesGrowth & -0.453 & 1.188 & 0.704 & & -0.892 & 0.267 & 0.001 & \\
TobinsQ & -2.128 & 0.189 & 0.000 & & -0.269 & 0.182 & 0.142 & \\
Age & -0.093 & 0.018 & 0.000 & & -0.009 & 0.005 & 0.057 & \\
\hline
\end{tabular}

Model 2

Keseluruhan Sampel

\begin{tabular}{lcccccccc}
\hline & \multicolumn{3}{c}{ Unstandardized } & \multicolumn{5}{c}{ Unstandardized } \\
\multicolumn{1}{c}{ Variabel } & Coefficients & Sig. & Sig. F & \multicolumn{2}{c}{ Coefficients } & Sig. t & Sig. t \\
& B & Std. & Error & & & B & Std. & Error \\
(Constant) & 0.594 & 2.076 & 0.775 & 0.000 & -3.471 & 0.751 & 0.000 & 0.000 \\
CcCon & -2.057 & 1.058 & 0.053 & & -0.471 & 0.303 & 0.125 & \\
Size & 0.025 & 0.148 & 0.868 & & 0.142 & 0.053 & 0.008 & \\
Lev & 0.428 & 0.205 & 0.038 & & 0.141 & 0.049 & 0.005 & \\
SalesGrowth & -0.090 & 1.208 & 0.941 & & -0.847 & 0.271 & 0.003 & \\
TobinsQ & -2.140 & 0.189 & 0.000 & & -0.277 & 0.183 & 0.134 & \\
Age & -0.094 & 0.018 & 0.000 & & -0.010 & 0.005 & 0.053 & \\
\hline
\end{tabular}

\section{Menilai Goodness of Fit Model}

Untuk menilai goodness of fit model

digunakan regresi linier berganda

dengan model regresi sebagai

berikut:

Model 1:

FD $=\alpha_{0}+\beta_{1} U C_{-} C_{\text {CON }}+\beta_{2} \operatorname{Size}_{i t}+\beta_{3} L e$

$\mathbf{v}_{\text {it }}+\beta_{4}$ Sales Growth $_{\text {it }}+\beta_{5}$ Tobins

$\mathrm{Q}_{\mathrm{it}}+\beta_{6} \mathrm{Age}_{\mathrm{it}}+\boldsymbol{e}$
Model 2:

$F D=\alpha_{0}+\beta_{1} C C_{-} C O N_{i t}+\beta_{2} S_{i z e}+\beta_{3} L e$

$\mathbf{v}_{\text {it }}+\beta_{4}$ Sales Growth $_{\text {it }}+\beta_{5}$ Tobins

$\mathrm{Q}_{\mathrm{it}}+\boldsymbol{\beta}_{6} \mathrm{Age}_{\mathrm{it}}+\boldsymbol{e}$

\section{Uji F}

Baik pengujian pada keseluruhan sampel maupun pada sampel perusahaan distress menunjukan nilai 
sig. $0,000<\alpha=0,05$ (dapat dilihat pada Tabel 8) menunjukkan bahwa secara simultan variabel unconditional conservatism, conditional conservatism, ukuran perusahaan, leverage, pertumbuhan penjualan, kinerja perusahaan, dan umur perusahaan berpengaruh terhadap financial distress.

\section{Uji t}

Pengujian model regresi 1 pada keseluruhan sampel menunjukan hanya varabel leverage, kinerja perusahaan, dan umur perusahaan terbukti berpengaruh terhadap financial distress, sedangkan sisanya tidak. Pengujian model regresi 2 pada keseluruhan sampel menunjukan hanya variabel conditional conservatism, leverage, kinerja perusahaan, dan umur perusahaan terbukti berpengaruh terhadap financial distress, sedangkan sisanya tidak.

Pengujian model regresi 1 dan 2 pada sampel perusahaan distress menunjukan seluruh variabel yaitu unconditional conservatism, conditional conservatism, ukuran perusahaan, leverage, pertumbuhan penjualan, kinerja perusahaan, dan umur perusahaan terbukti berpengaruh terhadap financial distress (seluruh hasil uji $\mathrm{t}$ dapat dilihat pada Tabel 8).

\section{Uji Koefisien Determinasi}

Pengujian model regresi 1 pada keseluruhan sampel menunjukan sebesar $43 \%$ variabel financial distress dapat dijelaskan oleh variabel unconditional conservatism dan kelima variabel kontrol. Sedangkan sisanya sebesar $57 \%$ dijelaskan oleh variabel lain. Pengujian model regresi 2 pada keseluruhan sampel menunjukan sebesar 43,5\% variabel financial distress dapat dijelaskan oleh variabel conditional conservatism dan kelima variabel kontrol. Sedangkan sisanya sebesar $56,5 \%$ dijelaskan oleh variabel lain.

Pengujian model regresi 1 pada sampel perusahaan distress menunjukan sebesar $30,3 \%$ variabel financial distress dapat dijelaskan oleh variabel unconditional conservatism dan kelima variabel kontrol. Sedangkan sisanya sebesar $69,7 \%$ dijelaskan oleh variabel lain. Pengujian model regresi 2 pada sampel perusahaan distress 
menunjukan sebesar $29,7 \%$ variabel financial distress dapat dijelaskan oleh variabel conditional conservatism dan kelima variabel kontrol. Sedangkan sisanya sebesar $70,3 \%$ dijelaskan oleh variabel lain.

\section{Pembahasan}

\section{Pengaruh}

\section{Unconditional \\ terhadap}

Conservatism

\section{Financial Distress}

Berdasarkan hasil uji t pada model regresi 1, dapat dilihat bahwa pengujian pada keseluruhan sampel diperoleh nilai sig (one-tailed) $0,209 / 2=0,105>\alpha=0,05$ dan koefisien beta bertanda negatif sebesar -1,333. Hal ini mengindikasikan bahwa variabel unconditional conservatism tidak cukup bukti berpengaruh terhadap financial distress namun memberikan arah negatif sesuai dengan hipotesis 1. Sebaliknya, pengujian pada sampel perusahaan distress diperoleh nilai sig (onetailed) $0,087 / 2=0,043<\alpha=0,05$ dan koefisien beta bertanda negatif sebesar $-0,500$. Hal ini mengindikasikan bahwa variabel unconditional conservatism terbukti berpengaruh terhadap financial distress dengan arah negatif. Hal ini juga sesuai dengan hipotesis 1. Maka dapat disimpulkan bahwa penerapan unconditional conservatism dapat mengurangi risiko terjadinya financial distress pada perusahaan. Hasil pengujian ini sesuai dengan hasil penelitian Poorzamani dan Anhari (2013).

Hasil ini menunjukan bahwa dengan adanya penerapan unconditional conservatism akan menghasilkan pelaporan laba yang lebih persisten dan nilai buku aset yang understated (Chan et al., 2009) sehingga akan berdampak baik bagi perusahaan salah satunya terhindar dari risiko terjadinya financial distress. Hal ini juga terkait dengan teori agensi, dimana konservatisme menyebabkan minimnya ruang gerak oportunistik manajemen. Tindakan oportunistik yang dapat dilakukan oleh manajemen seperti manajemen laba sehingga pelaporan laba menjadi overstated yang menyebabkan laporan keuangan menjadi bias dan tidak dapat memberikan gambaran secara utuh mengenai kondisi perusahaan yang sebenarnya dan nantinya akan membawa keputusan buruk yang dapat berdampak di masa 
depan (Lafond dan Watts, 2006). Unconditional conservatism juga menghasilkan peningkatan arus kas. Adanya peningkatan arus kas juga dapat mengurangi risiko terjadinya financial distress karena pada dasarnya kepailitan merupakan suatu kondisi awal dari ketidakcukupan kas (Wulandari, 2012).

\section{Pengaruh}

Conditional

Conservatism terhadap

\section{Financial Distress}

Berdasarkan hasil uji t pada model regresi 2, dapat dilihat bahwa pengujian yang dilakukan pada keseluruhan sampel diperoleh nilai sig (one-tailed) $0,053 / 2=0,027<\alpha$ $=0,05$ dan koefisien beta bertanda negatif sebesar $-2,057$ sedangkan pengujian yang dilakukan pada sampel perusahaan distress diperoleh nilai sig (one-tailed) $0,125 / 2=0,063$ $<\alpha=0,10$ dan koefisien beta bertanda negatif sebesar $-0,471$. Hal ini menunjukkan bahwa keduanya mengindikasikan variabel conditional conservatism terbukti berpengaruh terhadap financial distress dengan arah yang negatif. Hal ini sesuai dengan hipotesis 2 . Maka dapat disimpulkan bahwa penerapan conditional conservatism dapat mengurangi risiko terjadinya financial distress pada perusahaan Hasil pengujian ini sesuai dengan hasil penelitian Mamaghani dan Darabi (2016) dan Moridipour et al. (2014).

Penerapan conditional conservatism yang menerapkan pengakuan beban atau losses lebih cepat dari pada gains. Conditional conservatism juga menghasilkan jumlah non operating accrual yang tinggi karena membebankan akun-akun non operasional lebih sering meskipun beban atau losses tersebut belum benar-benar terjadi. Hal ini membantu perusahaan mengantisipasi segala bentuk kerugian yang akan terjadi sehingga perusahaan dapat mengambil keputusan yang tepat agar terhindar dari segala bentuk kerugian yang dapat mengancam keberlangsungan operasi perusahaan. Pengakuan beban-beban non operasi yang cenderung lebih cepat juga mengakibatkan pelaporan laba yang rendah dan tidak overstated sehingga dapat menggambarkan bahwa perusahaan terhindar dari sikap oportunistik manajemen seperti tindakan manajemen laba yang dapat 
meningkatkan risiko terjadinya financial distress (Lafond dan Watts, 2006). Penerapan konservatisme ini juga menghasilkan informasi yang memberikan dampak yang besar bagi manajer maupun pemangku kepentingan dalam sebuah perusahaan agar dapat mengambil keputusan yang optimal untuk masa depan yang tentunya akan menghindarkan perusahaan dari terjadinya financial distress (Moridipour et al. 2014).

\section{Simpulan dan Saran}

Berdasarkan hasil analisis yang telah dijabarkan sebelumnya, dapat diambil kesimpulan bahwa unconditional conservatism dan conditional conservatism terbukti berpengaruh negatif terhadap financial distress.

Mengingat adanya keterbatasan dalam penelitian ini, maka disarankan agar peneliti selanjutnya untuk menambah periode penelitian yang lebih panjang agar didapat hasil penelitian yang lebih komprehensif, menambah perusahaan dari sektor lainnya agar didapat hasil penilitian yang utuh dan dapat menggambarkan seluruh sektor perusahaan, menggunakan model pengukuran variabel financial distress yang lain seperti Springate dan Zmijewski, dan menggunakan variabel kontrol yang lain seperti good corporate governance dan corporate social responsibility.

\section{DAFTAR PUSTAKA}

Ahmed, A. S., Billings, B. K., Morton, R. M., \& StanfordHarris, M. (2002). The Role of Accounting Conservatism in Mitigating BondholderShareholder Conflicts over Devidend Policy and in Reducing Debt Costs. The Accounting Review Vol. 77, 867-890.

Altman, Edward I. (1968). Financial Ratios, Discriminant Analysis and The Prediction of Corporate Bankruptcy. The Journal of Finance. Vol. 23 No. 4: 589-609.

Anthony, R., \& Govindaradjan, V. (2015). Management Control System (Sistem Pengendalian Manajemen) Ed. 11 Buku 2. Jakarta: Salemba Empat.

Baldwin, C. Y., \& Mason, S. P. (1983). The Resolution of Claims in Financial Distress the Case of Massey Ferguson. The Journal of Finance. 
Basu, Sudipta. 1997. The Conservatism Principle and the Asymmetric Timeliness of Earnings. Journal of Accounting and Economics 24, 3-37.

Biddle, G., Kim, J., Ma, L., \& Song, F. (2010). Accounting Conservatism and Bankruptcy Risk. SSRN, 149.

Bowerman, B. L., O'Connel, R. T., \& Murphree, E. S. (2011). Business Statistics in Practice (6th ed.). New York: McGraw-Hill Irwin.

Chung, Kee H. \& Pruitt, Stephen W. A Simple Approximation of Tobin's Q. Financial Management. Vol. 23, No. 3: 70-74.

Cooper, D. R., \& Schindler, P. S. (2016). Metode Penelitian Bisnis Ed. 12 Buku 1. Jakarta: Salemba Empat.

Deviacita, Arieany W. \& Achmad, Tarmizi. (2012) Analisis Pengaruh Mekanisme Corporate Governance Terhadap Financial Distress. Diponegoro Journal of Accounting Vol. 1 No. 1: 114.

Fala, D. Y. (2007). Pengaruh Konservatisme Akuntansi Terhadap Penilaian Ekuitas Perusahaan Dimoderasi Oleh Good Corporate Governance. Simposium Nasional Akuntansi X.
Ghozali, I. (2013). Aplikasi Analisis Multivariat dengan Program IBM SPSS 21 Edisi 7. Semarang: Penerbit Universitas Diponegoro.

Givoly, D., \& Hayn, C. (2000). The Changing Time-Series Properties of Earnings, Cash Flows and Accruals: Has Financial Reporting become More Conservative. Journal of Accounting and Economics 29, 287-320.

Haniati, Sri. \& Fitriany. (2010). Pengaruh Konservatisme Terhadap Asimetri Informasi Dengan Menggunakan Beberapa Model Pengukuran Konservatisme. Simposium Nasional Akuntansi XIII Purwokerto 2010.

Lafond, Ryan., dan Watts, R.L. (2006). The Information Role of Conservative Financial Statements. Social Science Research Network Electronic Paper Collection.

Li, X. (2010). Accounting Conservatism and The Cost of Capital: International Analysis. London Business School.

Mamaghani, B. A., \& Darabi, R. (2016). The Relationship Between Conditional Conservatism and Financial Crisis. Asian Social Science Vol. 12 No.6. 
Maslachah, L., Wahyudi, S., \& Mawardi, W. (2015). Analisis Pengaruh Leverage, Tobin's Q, Intangible Asset, Tangibel Asset, Likuiditas, dan Ukuran Perusahaan Terhadap Prediksi Terjadinya Financial Distress (Studi pada Perusahaan Manufaktur yang Terdaftar di BEI Tahun 2010-2014). Artikel Magister Manajemen Universitas Diponegoro.

Moridipour, H., Mousavi, Z., \& Darash, F. (2014). Conditional Conservatism and Level of Bankruptcy. Euro-Asian Journal of Economics and Finance.

Platt, H. D., \& Platt, M. B. (2002). Predicting Corporate Financial Distress: Refrections on Choice-Based Sample Bias. Journal of Economics and Finance, 184.

Poorzamani, Z., \& Anhari, N. (2013). Studiying The Relationship Between Conditional and Unconditional Conservatism with Altman's Bankruptcy Model Index Evidenced From Iran. Life Science Journal.
Ramadhani, A.S., Lukviarman, N. (2009). Perbandingan Analisis Prediksi Kebangkrutan Menggunakan Model Altman Pertama, Altman Revisi, dan Altman Modifikasi dengan Ukuran dan Umur Perusahaan Sebagai Variabel Penjelas (Studi Pada Perusahaan Manufaktur yang Terdaftar Di Bursa Efek Indonesia). Jurnal Siasat Bisnis Vol. 13 No. 1.

Wardhani, R. (2006). Mekanisme Corporate Governance dalam Perusahaan yang Mengalami Permasalahan Keuangan (Financially Distressed Firms). Simposium Nasional Akuntansi 9 Padang.

Watts, R. (2003). Conservatism in Accounting Part I: Explanations and Implications. Accounting Horizons Vol.17, 207-221.

Widhiari, N. L., \& Merkusiwati, N. K. (2015). Pengaruh Rasio Likuiditas, Leverage, Operating Capacity, dan Sales Growth Terhadap Financial Distress. E-Jurnal Akuntansi Universitas Udayana.

Wulandari, F. (2012). Hubungan Simultan Antara Koservatisme Akuntansi dan Financial Distress pada Perusahaan Manufaktur yang Terdaftar di BEI Periode 2009-2010. Depok: Skripsi Mahasiswa Universitas Indonesia. 
Zamani, A. A., Piri, A., \& Heidari, S. (2014). Investigating The Relationship Between Accounting Conservatism and The Bankruptcy Risk Of Companies. Indian Journal of Fundamental and Applied Life Sciences ISSN Vol.4, 2024-2033.
Zhang, Jieying. (2008). The Contracting Benefits of Accounting Conservatism to Lenders and Borrowers. Journal of Accounting \& Economic No. 45: 27-54. 